\title{
The Realizations of Point of Departure of Message in General English Texts
}

\author{
Seyed Foad Ebrahimi \\ English Department, Shadegan Branch, Islamic Azad University, Shadegan, Iran \\ E-mail: seyedfoade@gmail.com
}

Received: 25-03-2017

Published: 01-11-2017
Accepted: 22-05-2017

doi:10.7575/aiac.ijalel.v.6n.6p.40
Advance Access Published: September 2017

URL: http://dx.doi.org/10.7575/aiac.ijalel.v.6n.6p.40

\begin{abstract}
This study aimed to investigate the realization of marked and unmarked theme types as point of departure of message in general English texts. The corpus of this study was 15 general English texts extracted from English general textbooks for university students published in Iran and taught at universities in Iran. The corpus was analyzed based on Halliday's (1985) framework of thematic organization. Findings suggested the unmarked theme was predominant compared to marked theme. This is due to that writers prefer to use simple structure that help readers to get a better comprehension. Findings also showed that different types of marked theme were used to help in text organization and contribute to better comprehension. In such cases, the writers felt the need to mention some elements in the thematic position other than grammatical subject. The findings highlighted that general English instructors and developers need to take on board the notion of theme and its importance in teaching and developing general English texts.
\end{abstract}

Keywords: Theme, marked theme, unmarked theme, general English text

\section{Introduction}

Academic written and spoken discourses have been studied in the last two decades for the rhetorical structures and linguistic features. One of the linguistic features that have been received attention was Halliday's notion of theme. Halliday (1985, p. 30) defines theme "as an element which serves as the point of departure of the message and what the speaker has in mind to start with. It is the element in a particular structural configuration taken as whole, and it organizes the clause as a message. The remainder of the message is called the rheme". Therefore, a clause consists of a theme combined with a rheme and the structure is expressed by order. The order for this is theme followed by rheme. In the same line, Brown and Yule (1983) stated that one of the constraints on the speakers /writers is that they can produce only one word at a time when they are producing their messages. They have to choose a beginning point for their utterances in order to organize their messages. The initial point is important in the clause and also in the discourse. It influence the hearers/readers' interpretation of everything that follows in the discourse since it constitute the initial textual context for everything that follows. What is placed in this initial position is called theme.

A number of studies have been carried out to find out the possible types of thematic organization and progression in different academic genres. Some of these studies (Borsinger, 2003; Ebrahimi, 2008; Ghadessy, 1999, 2001; Gosden, 1992, 1993; Jalilifar 2010; Jalilifar and Khedri 2011; Lores, 2004; Martinez, 2003; North, 2005; Whittaker, 1995) are reviewed below.

To find out the possible similarities and differences in case of thematic organization types and thematic progression patterns, Jalilifar (2010) analyzed research articles written by Iranian local and international writers. He ran his study on a corpus of 32 research articles, 16 written by Iranian local writers and 16 written by international writers. To analyze the corpus, Jalilifar (2010) used two models of thematic organization and thematic progression proposed by Halliday (1985) and McCabe (1999). The unit of analysis was t-unit. Jalilifar (2010) found similarities regarding thematic organization types in both corpora. He justified these similarities in terms of genre similarity. This means that similarity in genre engender similarity in textual choices. The result also showed that in both corpora textual, marked and multiple theme were implied more in result and discussion comparing to other sections, introduction and method. He explained this based on the argumentative nature of result and discussion suggesting that textual and marked are implied more to show the argumentative nature of result and discussion. The findings of his study suggested that the analyzed research articles had impersonal and factual tone. The low percentage of interpersonal theme could show that reader and writer are not systematically related to each other.

How students pack and progress the information thematically was studied by Ebrahimi (2008). He analyzed students' composition writings to find out the possible thematic organization types and thematic progression patterns and their relation to students' level of language proficiency. He built his study on a corpus of 240 compositions written by undergraduate students majoring in English language translation in Abadan Islamic Azad University in Iran. Eighty students were participated in this study. The result in terms of theme types applied by students in their compositions 
revealed a) more use of textual theme than interpersonal themes; suggesting the higher impersonality of students' writings, b) more application of simple than multiple; indicating the students' tendency toward using simple sentences in their compositions, and c) over-use of unmarked theme; showing students' preference of placing theme in the subject position, making sure that their sentences are grammatically correct, and at the same time, giving continuity to the text since the rheme or theme of the previous t-unit is used in the thematic position of the next clause and this connects the $t-$ units together.

In analyzing the thematic structure of the Method and Discussion sections of Biology research articles, Martinez (2003) ran her study on a corpus of 30 method and discussion sections of Biological science research articles. She selected the articles from 15 high quality journals. Analyzing the gathered data for the theme structure revealed significant differences between the method and discussion section regarding theme types. Interpersonal theme was mostly found in discussion section. Textual theme was used more than interpersonal theme. This theme was presented in method section by external temporal theme and in discussion section by adversative theme. In discussion section, multiple theme was four times more than that in method section. This suggests "the author's rhetorical effort to persuade readers" (p.119). In discussion section, some of the multiple themes included all, the three themes of interpersonal, textual, and topical. The result revealed that marked theme was mostly circumstantial. In method section, marked theme was mostly illustrated the purpose and time. The marked temporal theme used in this section was external temporal sequences, which organize the text from the time perspective with the focus on the chronological sequences of the steps of the research. The higher proportion of marked theme in discussion section contributes to "the logical organization of the text" (p.119). She found that unmarked theme was distributed interestingly in the method and discussion sections. More application of unmarked theme in discussion section also showed that this section could be more argumentative and abstract section. She finally argued that thematic choices are different across different sections of the research articles.

Exploring the thematic organization types and thematic progression patterns in English Applied Linguistics textbooks and their Persian translation was the focus of the study conducted by Jalilifar (2011). To build a representative corpus, they selected 18 Applied Linguistic textbooks, 9 in English and 9 in Persian. Halliday (1994) and McCabe's (1999) models of thematic organization and thematic progression were used to analyze the data. They found that translators included more textual themes in their texts, about two times, compared to the writers of the original texts. The result of their study reported that interpersonal theme was treated similarly in both texts. Both authors and translators dedicated small number of themes to interpersonal theme. They justified interpersonal theme underestimation on the ground that writer-reader relationship was not well-balanced. Their findings illustrated difference and similarities between the two corpora concerning marked and unmarked themes in order. Regarding manifestation of marked theme, the frequency of non-subject topical theme was higher in Persian results in more argumentative translations. Dealing with unmarked theme, the tendency was greatly toward presenting participants in the theme position. This indicated that in both textbooks the sentences were active, and both authors and translators used this theme to give continuity and maintain coherence between the sentences. They also found similarity in case of simple theme, but difference in case of multiple theme, with more application in translated texts. They also ran chi-square on the data to see the significance of the differences reported by the results. The differences were statically meaningful in terms of textual, multiple, and marked themes.

Ebrahimi and Chan (2015) explored and compared the discourse functions of unmarked theme (grammatical subjects) used in research article abstracts from two disciplines namely Applied Linguistics and Economics. They ran their study on a corpus of 60 research article abstracts published in 2010 and 2011 . The research articles were extracted from two journals namely Applied Linguistics and Oxford Economic Papers. They analyzed the corpus based on the classification of discourse functions of unmarked theme (grammatical subjects) suggested by Gosden (1993). The results reported some disciplinary differences regarding the discourse functions enacted by the application of the unmarked theme types. The findings of their study could add to academic writing (e.g. research article abstract) is imposed by the writer's disciplinary background with particular reference to the use of the unmarked theme.

The reviewed literatures indicate that most of the attention was devoted to the study of the realization of marked and unmarked theme in research article and research article abstracts. Thus this study intends to shed the light on the realizations of marked and unmarked themes in general English textbooks taught at Iranian universities.

\section{Methodology}

\subsection{Design and Corpus}

This study is following the mix-method design. In this study not only the frequency but also the functions of themes were reported and discussed. This study was carried out on a corpus of 15 general English texts extracted from English general textbooks for university students published in Iran and taught at universities in Iran.

2.2 Framework of analysis

Halliday (1985, p. 54) classified theme as follows:

1. Topical theme: this is presented by a nominal group (e.g., everyone), a prepositional phrase

(e.g., with ships continually at sea), or an adverbial group (e.g., by the middle of 15 th century).

2. Interpersonal theme: this is consisted of any blend of vocatives (direct addresses such as: personal names), modal adjuncts and mood marking elements (finite verbal operator (temporal \& modal), WH-interrogatives and imperative let's. 
3. Textual theme: this is presented through continuatives (small set of discourse items which signal that a new move is beginning, such as: yes, no, oh...), structural elements (coordinates \& subordinates) and conjunctive adjuncts which relate the clause to the preceding texts (e.g., in other words).

The other classification proposed by Halliday (1985) is marked and unmarked themes. Unmarked theme is realized when one element occupies two positions of grammatical subject and thematic.

"Example: $\underline{\text { she }}$ went back downstairs."

Marked theme is realized when an element other than the subject occupies the theme position, so a condition is created for the appearance of marked theme (p.44).

"Example: when she opened the door, she screamed at him like a crazy person."

\subsection{Unit of analysis}

This study implement t-unit as the unit of analysis. T-unit is defined by Fries (1994) "as a clause complex which contains one main independent clause together with all the hypotactic clauses which are dependent on it" (p.318). The rationale behind this selection was that:

"Analyzing theme at the level of t-unit rather than the individual clause makes it easier to focus on patterns of thematic development in large amounts of text, and can also be justified on the grounds that the thematic structure of a dependent clause is often constrained by the independent clause" (Fries \& Francis, 1992).

\subsection{Procedure of Analysis}

To analyze the corpus, the following procedures were followed: First, the textbooks from which corpus was extracted were selected. Second, texts were selected and changed to word files. Third, the t-units were identified. Forth, theme of each t-unit was identified. Fifth, the findings were tabulated and discussed.

\section{Results and Discussion}

The corpus was analyzed for marked and unmarked themes and the results are plotted in Table 1.

Table 1. Frequency of marked and unmarked theme

\begin{tabular}{lll}
\hline Theme type & Frequency & Percentage \\
\hline Unmarked theme & 249 & $72 \%$ \\
\hline Marked theme & 96 & $28 \%$ \\
\hline Total & 345 & $100 \%$ \\
\hline
\end{tabular}

The results presented in Table 1 indicate that unmarked theme (Example 1) is used greater than marked theme (Example 2). This is in line with findings reported in Ebrahimi and Chan (2013) and Ebrahimi (2016 a). This similarity might suggest that disregarding the academic genre of analysis, writers in academic texts prefer to use topical unmarked theme in the thematic position. Such a use could be discussed based on the fact that in academic texts, writers prefer to use simple structures and to develop texts that follow the simple structure of sentence in English at which sentences are started by grammatical subject at the thematic position followed by verbs. The other justification could be that writers do not feel the need to situate any information before the grammatical subject and prefer to present grammatical subject in the thematic position. This might suggest that generally academic texts do not requires writers to shift topics that result in less need of marked theme.

"Example 1: $\underline{\text { she }}$ marched upstairs to remind him of his promise."

"Example 2: On Saturday, his friends would come over and I would get to a whole band".

The corpus was analyzed for marked theme types and the results are plotted in Table 2.

Table 2. marked theme types

\begin{tabular}{llll}
\hline & Marked theme types & Frequency & Percentage \\
\hline 1 & Time & 32 & $34 \%$ \\
\hline 2 & Condition & 24 & $25 \%$ \\
\hline 3 & Contrast & 16 & $17 \%$ \\
\hline 4 & Sequence & 10 & $10 \%$ \\
\hline 5 & Addition & 6 & $6 \%$ \\
\hline 6 & Validation & 3 & $3 \%$ \\
\hline 7 & Purpose & 3 & $3 \%$ \\
\hline 8 & Cause & 2 & $2 \%$ \\
\hline
\end{tabular}

Time marked theme (Example 3) was use greater compared to other types of marked themes. This finding is in line with Ebrahimi (2016 b) and in contrast with Ebrahimi and Chan (2016) findings. This might suggest that the genre of analysis could have required writers to select this type of marked theme. 
"Example 3: Last year we had a storm that blew half of our roof off."

This marked theme type was used to a) sequence events (Example 4) and b) present the time contexts of presented information (Example 5).

"Example 4: The very next day, he blasted his stereo."

"Example 5: Every year her landlord raises the rent five percent."

The next more frequent marked theme type is condition (Example 6). The finding plotted in Table 2 concerning the condition marked theme is in line with Ebrahimi and Chan (2016) and in contrast with Ebrahimi, Chan and Tan (2015) findings. This might suggest that textbook writers prefer to situate the condition based on which the attached information could make sense in the thematic position. The similarity and differences between the result of this study and other studies in literature might suggest that the selection and frequency of the condition marked theme is highly related to the genre of analysis.

"Example 6: Nervously, the young female teller handed the man three big bags loaded with cash."

The condition marked theme was used mostly to present a) the condition for the attached information (Example 7) and b) the information in a form of cause and effect (Example 8).

"Example 7: Sweating and dizzy, she left a cigarette out of one pack."

"Example 8: If he wanted to see the pyramids, she said he could rent a video or Google the pyramids online."

The third marked theme type is the contrast marked theme (Example 9). The result plotted in Table 2 concerning the contrast marked theme is in line with Ebrahimi et al. (2015) and Ebrahimi and Chan (2016) findings. It seems that the use of this marked theme could help in creating a negative relation between the information.

"Example 9: occasionally, the police received reports about people being pick pocketed while waiting in the overnight lines. $\underline{B \boldsymbol{u} t}$ such reports were rare."

The contrast marked theme was used to contrast the information reported which could act as strategy to catch the attention of readers (Example 10).

"Example 10: Even though he loved the convenience of home delivery, Alfred's sleep was far more valuable to him."

The sequence marked theme was used for $10 \%$ of marked theme types realized in the analyzed corpus. This result is in contrast with results reported by Ebrahimi et al. (2015) and Ebrahimi (2016 b). This might suggest that in textbooks, writers prefer to present information in sequence of their appearance (Example 11).

"Example 11: He yelled at her and then hit her sharply across her back with rod. Then the bodyguard kicked her in stomach."

The other three types of marked theme have received little attention. This might suggest that in textbooks, writers do not feel the need to realize these marked theme types with high frequency.

\section{Conclusion}

This study aimed to investigate the realizations of marked and unmarked theme in general English textbooks taught at Iranian universities. The corpus was analyzed and findings suggested the greater use of unmarked theme compared to marked theme.

In the preceding section, it is mentioned that the predominance of unmarked theme is due to the fact that in general English texts, writers prefer to use simple structure that help readers to get a better comprehension. In the cases where the writers felt the need to mention some elements in the thematic position other than grammatical subject, they resorted to the use of marked theme. Such a structure could help in text organizations that act an important role in increasing the text comprehension. The findings reported in this study could general English instructors and developers in taking the notion of theme and its importance in teaching and developing general English texts.

"This study was supported by a grant number (15003) from Islamic Azad University, Shadegan Branch, Iran. The grant entitled: Thematicity in pre-requisite, general, and English for specific purposes textbooks, aim at finding thematic structures with the implication to help syllabus designers.”

\section{References}

Borsinger, A. M. (2003). A comparison of the thematic options in novice and experts research writings. Studios de Lingustica Aplicada Julio ,37 (21), 37-51.

Brown, G., \& Yule, G. (1983). Discourse analysis. Cambridge University Press.

Ebrahimi, S. F. (2008) Thematic organization and thematic progression in Iranian EFL composition writing: Implication in teaching writing skill Unpublished master's thesis. Islamic Azad University, Science and Research Branch Press: Ahvaz.

Ebrahimi, S. (2016a). Theme Types and Patterns in Research Article Abstracts: A Cross Disciplinary Study. International Journal of English Language \& Translation Studies, 4(3), 104-115. 
Ebrahimi, S. F. (2016b). Initial sentence elements in environmental engineering research article method sections. Language \& communication, 3(2), 215-229.

Ebrahimi, S. F., \& Chan, S. H. (2013). Manifestation of theme as a point of departure in the result and discussion section of academic research articles. Pertanika Journal of Social Sciences \& Humanities, 21(spec. Nov.), 29-40.

Ebrahimi, S. F., Swee, H. C., \& Helen, T. (2015). Choice and use of context frames to augment the writing of result and discussion section of research articles across four disciplines. 3L; Language, Linguistics and Literature, The Southeast Asian Journal of English Language Studies., 21(1), 71-80.

Ebrahimi, S. F., \& Chan, S. H. (2016). Cross-disciplinary use of organizational linkers in research article abstracts. International Journal of Foreign Language Teaching and research, 4 (15), 63-74.

Fries, P. H. (1994). Theme, method of development, and texts . World Englishes 21(2), 317- 359.

Fries, P. H. \& Francis, G. (1992). Exploring theme: Problems for research. Occasional Papers in Systemic Linguistics 6, 45-60.

Ghadessy, M. (Ed.). (1999). Text and context in functional linguistics (Vol. 169). John Benjamins Publishing.

Ghadessy, M., \& Gao, Y. (2001). Comparing thematic organization in two languages. Small corpus studies and ELT: Theory and practice, $5,335$.

Gosden, H. (1992). Discourse functions of marked theme in scientific research articles. Journal of English for Specific Purposes 11, 207-224.

Gosden, H. (1993). Discourse functions of subject in scientific research articles. Applied Linguistics 14(1), 56-75.

Halliday, M.A.k. (1985). An introduction to functional grammar. London: Britain: Edward Arnold.

Jalilifar, A. (2010). The status of theme in applied linguistics articles. The Asian ESP Journal 6 (2), 7-39.

Jalilifar, A. R. \& Khedri, M. (2011), “Thematic Development in English and Translated Academic Text”, in Jalilifar, A. R. \& Abdollahzadah, E. (eds.), Academic Research Genre in Asian Context, Ahwaz: Shahid Chamran University Press, pp. $335-364$.

McCabe, A. M. (1999). Theme and thematic patterns in Spanish and English history texts (Doctoral dissertation, University of Aston in Birmingham).

Martinez, I. A. (2003). Aspects of theme in the method and discussion sections of biology journal article in English. Journal of English for Academic Purpose, 2, 103-123.

North, S (2005). Disciplinary variation in the use of theme in undergraduate essays. Journal of Applied Linguistics, $26.3,431-452$.

Lores, R. (2004). On RA abstracts: From rhetorical structure to thematic organization. Journal of English for Specific Purposes 23, 280-302.

Whittaker, R. (1995). Theme processes and the realisation of meaning in academic articles. In M. Ghadessy(Eds.), Thematic development in English text (pp. 105 - 128). London: Pinter. 